\title{
Assessment of Soil Compaction Related to the Bulk Density with Land use Types on Arable Land
}

\author{
Hee-Rae Cho*, Kang-Ho Jung, Yong-Seon Zhang, Kyung-Hwa Han, Ahn-Sung Roh', Kwang-Rae Cho ${ }^{1}$, \\ Soo-Jeong Lim², Seung-Chul Choi ${ }^{2}$, Jin-il Lee ${ }^{3}$, Yeo-Uk Yun ${ }^{3}$, Byoung-Gu Ahn ${ }^{4}$, Byeong-Ho Kim ${ }^{5}$, \\ Jun-Hong Park ${ }^{6}$, Chan-Yong Kim ${ }^{6}$, and Sang-Jo Park ${ }^{6}$ \\ National Academy of Agricultural Science, RDA, Suwon 441-707, Korea, \\ ${ }^{1}$ Gyeonngi-do ARES, Hwaseong, 445-784, Korea, ${ }^{2}$ Gangwon-do ARES, Chuncheon, 200-150, Korea \\ ${ }^{3}$ Chungnam ARES, Yessan, 340-861, Korea, ${ }^{4}$ Jeollabuk-do ARES, Iksan, 570-704, Korea \\ ${ }^{5} J e o l l a n a m-d o ~ A R E S$, Naju, 520-715, Korea, ${ }^{6}$ Gyeongbuk ARES, Daegu, 702-708, Korea \\ ARES : Agricultural Research \& Extension Services
}

(Received: September 2 2013, Accepted: September 17 2013)

Soil compaction is affected by soil texture, organic matter (OM), strength (ST) and soil moisture, which is difficult to understand the degree and effects of related factors. The purpose of the study is to assess the impact of them on the compaction with bulk density (BD). The analysis was conducted with data collected from national-wide monitoring sites including 105 upland soils, 246 orchard soils, and 408 paddy soils between 2009 and 2012. The distributions of soil physical properties were measured. The correlation and multi linear regression analysis were performed between soil physical properties using SAS. The regression equation of BD(y) includes ST, gravitational water contents (GWC), and OM as variables commonly, having additional factors, clay content and sand content in paddy soil and upland soil for only subsoil $(\mathbf{p}<\mathbf{0 . 0 0 1})$. Our results show that the BD could be explained about $40 \sim 50 \%$ by various physical properties. The regression was mainly determined by ST in orchard and upland soil and by the GWC in paddy soil. To mitigate soil compaction, it is important to maintain the proper level of $\mathrm{OM}$ in upland soil and to consider the moisture condition with soil texture in paddy soil when making work plan. Furthermore, it would be recommended the management criteria classified by soil texture for the paddy soils.

Key words: Soil bulk density, Soil compaction, Land use type, assessment of soil physical properties

Analysis of regression with land use types.

\begin{tabular}{|c|c|c|c|c|c|c|c|c|c|}
\hline \multirow{2}{*}{$\begin{array}{l}\text { Land } \\
\text { use type }\end{array}$} & \multirow[b]{2}{*}{$\mathrm{n}$} & \multirow{2}{*}{ Depth } & \multirow{2}{*}{$\mathrm{R}^{2}$} & \multirow{2}{*}{ Intercept } & \multicolumn{5}{|c|}{ Parameter Estimate (Partial R-square) } \\
\hline & & & & & Strength & $\mathrm{GWC}^{\dagger}$ & $\mathrm{OM}^{\ddagger}$ & Clay & Sand \\
\hline \multirow{2}{*}{ Upland } & \multirow{2}{*}{105} & Topsoil & 0.36 & $1.414^{* * *}$ & $\begin{array}{c}0.017^{* * *} \\
(0.23)\end{array}$ & $\begin{array}{c}-0.009^{* *} \\
(0.08)\end{array}$ & $\begin{array}{c}-0.004^{* *} \\
(0.05)\end{array}$ & - & - \\
\hline & & Subsoil & 0.40 & $1.380^{* * *}$ & $\begin{array}{c}0.011^{* * *} \\
(0.26)\end{array}$ & - & $\begin{array}{c}-0.004^{* *} \\
(0.08)\end{array}$ & $\begin{array}{c}0.004^{* *} \\
(0.05)\end{array}$ & - \\
\hline \multirow{2}{*}{ Orchard } & \multirow{2}{*}{246} & Topsoil & 0.59 & $1.288^{* * *}$ & $\begin{array}{c}0.015^{* * *} \\
(0.38)\end{array}$ & $\begin{array}{c}-0.006^{* * *} \\
(0.07)\end{array}$ & $\begin{array}{c}-0.004^{* * *} \\
(0.14)\end{array}$ & - & - \\
\hline & & Subsoil & 0.38 & $1.425^{* * *}$ & $\begin{array}{c}0.011^{* * *} \\
(0.09)\end{array}$ & $\begin{array}{c}-0.007^{* * *} \\
(0.06)\end{array}$ & $\begin{array}{c}-0.006^{* * * *} \\
(0.22)\end{array}$ & - & - \\
\hline \multirow{2}{*}{ Paddy } & \multirow{2}{*}{408} & Topsoil & 0.52 & $1.961^{* * *}$ & $\begin{array}{l}-0.004^{*} \\
(0.01)\end{array}$ & $\begin{array}{c}-0.014^{* * *} \\
(0.44)\end{array}$ & $\begin{array}{l}-0.002^{*} \\
(0.01)\end{array}$ & $\begin{array}{c}-0.005^{* * *} \\
(0.05)\end{array}$ & $\begin{array}{c}-0.001^{* *} \\
(0.01)\end{array}$ \\
\hline & & Subsoil & 0.47 & $1.864^{* * *}$ & $\begin{array}{c}0.008^{* * *} \\
(0.04)\end{array}$ & $\begin{array}{c}-0.017^{* * *} \\
(0.41)\end{array}$ & $\begin{array}{c}-0.001^{*} \\
(0.01)\end{array}$ & $\begin{array}{c}-0.002^{*} \\
(0.01)\end{array}$ & $\begin{array}{c}-0.001^{* *} \\
(0.01)\end{array}$ \\
\hline
\end{tabular}

*Corresponding author : Phone: +82312900331, E-mail: Email: chohr519@korea.kr

${ }^{\S}$ Acknowledgement: This study was supported by grant of "Cooperative Research Program for Agricultural Science \& Technology Development (Project No. PJ006906)", Rural Development Administration, Republic of Korea. 


\section{Introduction}

토양다짐 (soil compaction)은 물리성 퇴화의 주요원인으로 꼽히고 있으며 (German soil protection law, 1998; European soil framework directive, 2006), 전세계적으로 작물생산과 환경문제의 위협으로 대두되고 있다 (Van Ouwerkerk and Soane, 1994; Soane and van Ouwerkerk, 1995). 농기계로 인해 전세계적으로 약 68 만 ha가 다짐된 토양으로 예측되 며 (Flowers and Lal, 1998), 유럽에서는 33만 ha 면적이 퇴 화되었다고 예상하고 있다 (Akker and Canarache, 2001). 우리나라 논토양의 $44.1 \%$ 정도가 심토의 물리성을 개량할 대상이라고 하였다 (Kim et al., 2006). 대형농기계 사용연 수 증가에 따라 용적밀도 및 경도가 증가되고 경운심 감소 가 나타났다고 보고되었다 (Han et al., 2010). 농작업의 기 계화는 우리의 농업환경 여건에서 필연적이며 이로 인해 발 생하는 토양다짐은 토양물리성 관리 측면에서 다루어져야 할 것이다.

토양다짐은 토성, 유기물 함량, 경도, 토양수분상태 등 여러 요인에 따라 달라지지만 이러한 다양한 요인이 다짐에 영향을 주는 정도와 여부를 파악하기에는 무리가 있다. 유 기물은 토양구조를 안정화시켜(Cochrane and Aylmore, 1994) 토양공극을 증대시킴으로써 용적밀도를 낮추는 기능 적 효과와 유기물 자체의 무게가 작아 용적밀도를 작게 하 는 본질적 특성이 있어 이 두 가지 요인이 용적밀도에 영향 을 끼칠 수 있다. 또한 토양의 수분함량이 많아지면 토양구 조의 변형에 취약해지며 (Lipiec et al, 2002), 이때 토양구 조변형이 일어나는 토양수분범위는 점토함량과 광물학적 특성에 따라 달라진다 (Spoor and Godwin, 1978). 즉, 다짐 이 최대로 발생하는 토양수분범위가 토성별로 다르다. 따라 서 다짐이 일어날 때 많은 인자가 관여하기 때문에 토양의 물리적 상태를 객관적으로 진단하고 편의적으로 예측하기 위해서 정량적 접근이 필요하다.

전세계적으로 토양의 질적 평가(Soil physical quality assessment)는 작물생산환경 보전차원에서 중요하게 생각 하며 유효한 질 지표개발 연구를 중심으로 수행되어 왔다. 브라질에서는 토양수분범위를 이용하여 Oxisol의 물리성을 평가하였으며 (Cassio et al., 1999), 용적밀도와 토양수분 상태를 이용하여 토양물리성 질 지표를 개발하고 (Reynolds et al., 2002), 작물의 영향을 고려하여 유기물함량, 용적밀 도, 토성 외에도 뿌리생육에 대한 효과를 고려하여 질 지표 를 개발하였다 (Dexter, 2004). 국내에서는 토양경도가 완 두뿌리의 신장에 미치는 영향 (Jo et al., 1977), 토성과 용 적밀도가 대두의 뿌리 생장특성에 미치는 영향 (Jung and $\mathrm{Lim}, 1989)$ 등 토양인자에 대한 특정작물의 생육반응에 대 한 연구가 있었다. 넓은 범위에서는 논토양 지형별 물리화 학적 특성을 분석하였고 (Hur et al., 1997), 논토양에서 용
적밀도에 대한 유기물과 토성의 관계를 구명하는 연구가 있 었다 (Hur et al., 1993). 지금까지 특정조건에서의 다짐연 구와 지역에 제한된 연구가 수행되었는데, 현재 중요하게 다루어지는 정밀 토양관리와 데이터 활용의 객관성을 확보 하기 위해서는 좀더 광범위한 지역에서 토양특성별로 물리 적 특성들 간의 관계를 분석하고 이를 토대로 진단하는 것 이 필요한데, 이에 대한 연구가 부족한 실정이다. 한편 토양 다짐에 대한 지표로써 경도와 용적밀도를 대표적으로 꼽는 다. 토양경도는 (soil strength) 식물의 뿌리뻗음에 대한 토 양의 저항성을 측정하는 (Taylor, 1971; Panayiotopoulos et al., 1994; Hamaza and Anderson, 2003) 것으로 다짐에 따 른 토양구조를 평가하는데 널리 사용된다 (Guerif, 1994; Horn and Rostek, 2000). 용적밀도는 일정부피에 담긴 건 조한 토양의 무게로 토양다짐과 물이나 공기의 토양 내 보 유 정도의 관계가 분명하기 때문에 토양의 다짐상태를 나타 내는데 가장 많이 쓰인다 (Panayiotopoulos et al., 1994). 공통적으로 용적밀도와 경도는 수분변화에 따라 값의 변이 가 발생하기 때문에 이에 따른 영향을 없애기 위해서는 수 분함량을 표준화 해주는 것이 필요하다 (Busscher, 1990). 측정방식상 경도는 원뿔의 끝을 토양지면에 대고 압력을 가 했을 때 저항값을 측정하는 것이기 때문에 점 측정치(point measurement)이며, 따라서 용적밀도에 비하여 공간변이가 상대적으로 크다 (Lipiec and Hatano, 2003). 이러한 점을 고려하여 토양다짐을 나타내는 지표로 용적밀도를 사용하 였다.

본 연구에서는 2009년부터 2012년까지 전국을 대상으로 조사한 토양물리성 (농촌진흥청, 2012) 결과를 바탕으로 최 근 토양물리성의 분포를 파악하고, 토양다짐의 지표로써 용 적밀도를 중심으로 이에 영향을 주는 인자들을 분석하고 그 들의 관계를 구명하고자 하였다.

\section{Materials and Methods}

조사대상지 특성 및 시료 채취 방법 2009년부터 2012년까지 각 도 농업기술원(경남, 제주 제외)과 국립농업 과학원 공동으로 전국농경지를 대상으로 토지이용별로 토 양물리성 조사를 수행하였다. 조사대상지는 밭토양 105지 점, 과수원 토양 246지점, 논토양 408지점이었다. 조사시기 는 밭토양과 과수원 토양는 토양 수분 조건이 포장용수량 이하이며 동결되지 않은 상태에서 경운시기를 제외하였고, 논토양은 수확 후 논물을 뺀 상태에서 조사가 이루어졌으 며, 시료채취 부위는 기계적 다짐의 영향이 적은 이랑 중에 서 작물이 심겨진 사이에서 하였다. 토양물리성은 토지이용 에 따라 시료 채취방법이 달라지며 시료채취과정 중 오차가 크기 때문에 조사대상별로 조사기준 및 분석방법에 준하여 조사가 이루어졌다(국립농업과학원, 2010). 
토양 물리성 분석 조사항목은 표토심, 산중식경도, 용적밀도, 삼상, 토성, 유기물 함량이었다. 토양단면에서 토성, 토색, 구조 등이 변하는 층위를 표토심으로 보고, 이 를 기준으로 표토와 심토로 나누고 각 층위에서 시료를 채 취, 물리성 조사를 하였다. 지표면으로부터 $3 \sim 4 \mathrm{~cm}$ 아래 에서 표토에 대한 채취, 조사를 하였고, 표토심에서 $5 \mathrm{~cm}$ 아랫부분에서 심토에 대한 채취, 조사를 하였다. 경도는 산 중식 경도계 (DIK-5553, strength of spring $78.4 \mathrm{~N} / 40 \mathrm{~mm}$, cone angle $25^{\circ}, 20^{\prime}$, Japan) 로 측정하였으며, 용적밀도 및 삼상은 $100 \mathrm{~cm}^{3}$ 코어법으로, 토성은 비중계법 (Hydrometer ASTM 152H) 및 피펫법 (Pipette)으로, 유기물은 Tyurin법 으로 분석하였다(NIAST. 2000.).

통계분석 두 가지를 전제로 연구를 수행하였는데, 모 델개발시 토양특성을 잘 반영하되, 너무 많은 변수로 복잡 해져서 모델로써의 기능이 떨어지지 않는 범위에서 인자의 수를 조절하였으며, 토양수분상태, 작부체계, 경운 및 기후 변화에 따라 다짐의 강도가 달라지며 영향을 끼치는 요인이 달라지기 때문에 (Boizard et al., 2001) 논 토양, 밭 토양, 과수원 토양 등 토지이용별로 분석하였다.

1 차적으로 용적밀도, 액상률, 기상률, 모래함량, 미사함 량, 점토함량, 경도, 중량수분함량, 유기물 함량 각각의 항 목 간에 관계가 있는지를 파악하기 위하여 상관분석을 하였 다. 2 차적으로 상관분석에서 유의성이 있게 나온 경도, 중 량수분함량, 유기물함량, 점토함량, 모래함량이 용적밀도를 결정하는데 얼마만큼의 영향을 끼치는지 알아보기 위하여 용적밀도를 종속변수로 놓고 stepwise로 변수를 취하여 다 중회귀분석을 하였다. 이에 대해 SAS 9.2 (SAS, USA)를 이 용하였다.

\section{Results and Discussion}

\section{토지이용별 토양물리성 분포 밭토양에서는 용적밀} 도가 표토의 약 $80 \%$ 가 $1.21 \sim 1.60 \mathrm{Mg} \mathrm{m}^{-3}$ 에서, 심토의 약 $93 \%$ 가 1.41 2.00 $\mathrm{Mg} \mathrm{m}^{-3}$ 에서 분포를 보였으며 (Fig. 1), 경도는 표토가 $10 \mathrm{~mm}$ 이하에서 가장 많이 분포하되 (약 $44 \%$ ), 약 $83 \%$ 가 $15 \mathrm{~mm}$ 이하에서, 심토가 $20.1 \sim 25.0 \mathrm{~mm}$ 에서 가장 많고(44\%), 약 80\%가 $15.1 \sim 25.0 \mathrm{~mm}$ 에서 분포 를 나타냈고 (Fig. 2), 유기물 함량은 표토의 $50 \%$ 이상이 $10.1 \sim 20 \mathrm{~g} \mathrm{~kg}^{-1}$ 에서 분포하며, 약 $83 \%$ 가 $10.1 \sim 30 \mathrm{~g} \mathrm{~kg}^{-1}$ 에서, 심토는 $10 \mathrm{~g} \mathrm{~kg}^{-1}$ 이하에서 가장 많이 분포(47\%)하되, $84 \%$ 가 $20.0 \mathrm{~g} \mathrm{~kg}^{-1}$ 이하였다 (Fig. 3).

과수원 토양에서는 용적밀도가 표토의 약 $73 \%$ 가 1.0 $1.40 \mathrm{Mg} \mathrm{m}^{-3}$ 에서, 심토의 약 $87 \%$ 가 $1.21 \sim 1.60 \mathrm{Mg} \mathrm{m}^{-3}$ 에서 분포를 보였고 (Fig. 1), 경도는 표토의 약 $77 \%$ 가 10.1 $20.0 \mathrm{~mm}$ 에서, 심토의 약 $92 \%$ 가 $15.1 \sim 25.0 \mathrm{~mm}$ 이었고
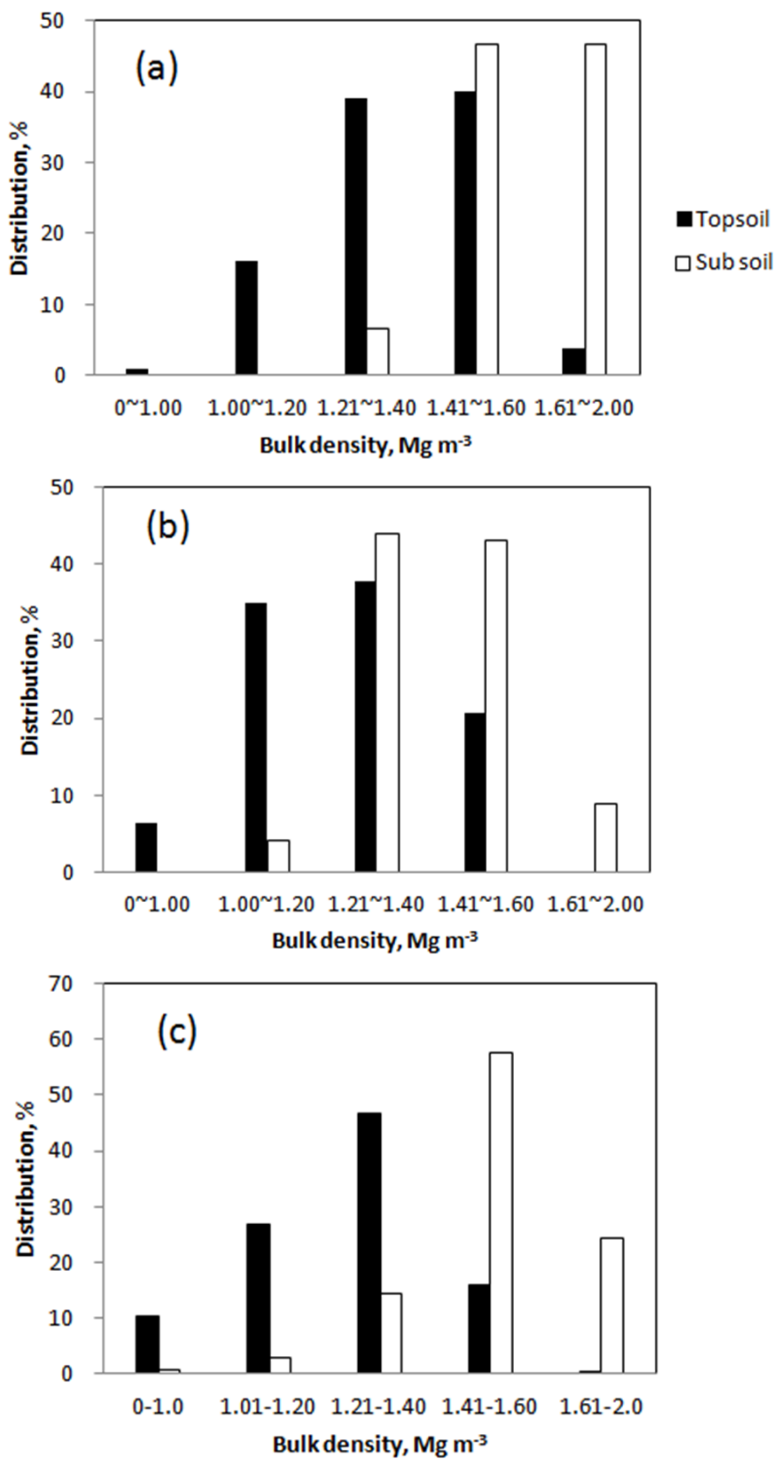

Fig. 1. Distribution of the bulk density with land use types. (a) Upland, (b) Orchard, (c) Paddy.

(Fig. 2), 유기물 함량은 표토가 20.1 30.0 g kg${ }^{-1}$ 에 가장 많이 분포하며 (약 $37 \%$ ) 이 값을 중심으로 정규분포를 이루 고 있었고, 심토는 $10.1 \sim 20.0 \mathrm{~g} \mathrm{~kg}^{-1}$ 에서 가장 많이 분포하 되 (약 $38 \%$ ), $20.0 \mathrm{~g} \mathrm{~kg}^{-1}$ 이하에서 $70 \%$ 이었다 (Fig. 3).

논토양에서는 용적밀도가 표토의 약 $74 \%$ 가 $1.01 \sim 1.40$ $\mathrm{Mg} \mathrm{m}^{-3}$ 에서, 심토의 약 $82 \%$ 가 $1.41 \sim 2.00 \mathrm{Mg} \mathrm{m}^{-3}$ 에서 분 포를 보였으며 (Fig. 1), 경도는 표토의 약 79\%가 10.1 $20.0 \mathrm{~mm}$ 에서 심토의 약 $91 \%$ 가 $15.1 \sim 25.0 \mathrm{~mm}$ 에서 가장 많은 분포를 보였고 (Fig. 2), 유기물 함량은 표토의 약 $73 \%$ 가 $10.1 \sim 30 \mathrm{~g} \mathrm{~kg}^{-1}$ 에서 심토의 $72 \%$ 가 $20.0 \mathrm{~g} \mathrm{~kg}^{-1}$ 이하에 서 분포하되, $10.1 \sim 20.0 \mathrm{~g} \mathrm{~kg}^{-1}$ 에서 $43 \%$ 로 가장 높은 분포 를 보였다 (Fig. 3).

우리나라 논토양의 개량 목표치가 용적밀도 기준으로 표 토 $1.20 \mathrm{Mg} \mathrm{m}^{-3}$, 심토 $1.40 \mathrm{Mg} \mathrm{m}^{-3}$ 이하, 심토 토양 경도 기준으로 $20 \mathrm{~mm}$ 이하임을 참고할 때 (Kim et al., 2013), 


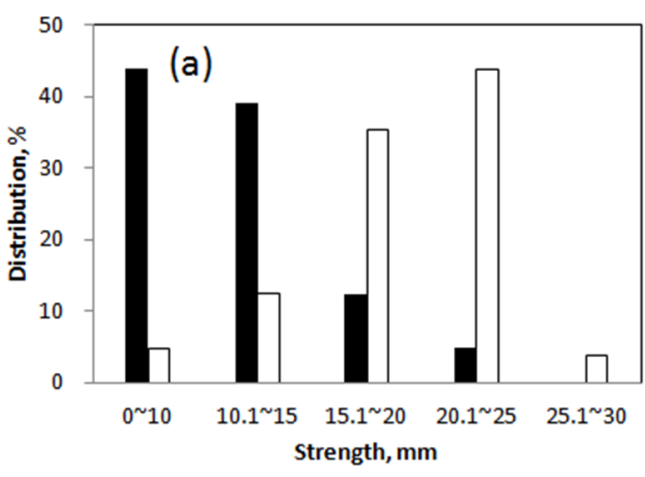

-Topsoil

$\square$ Sub soil
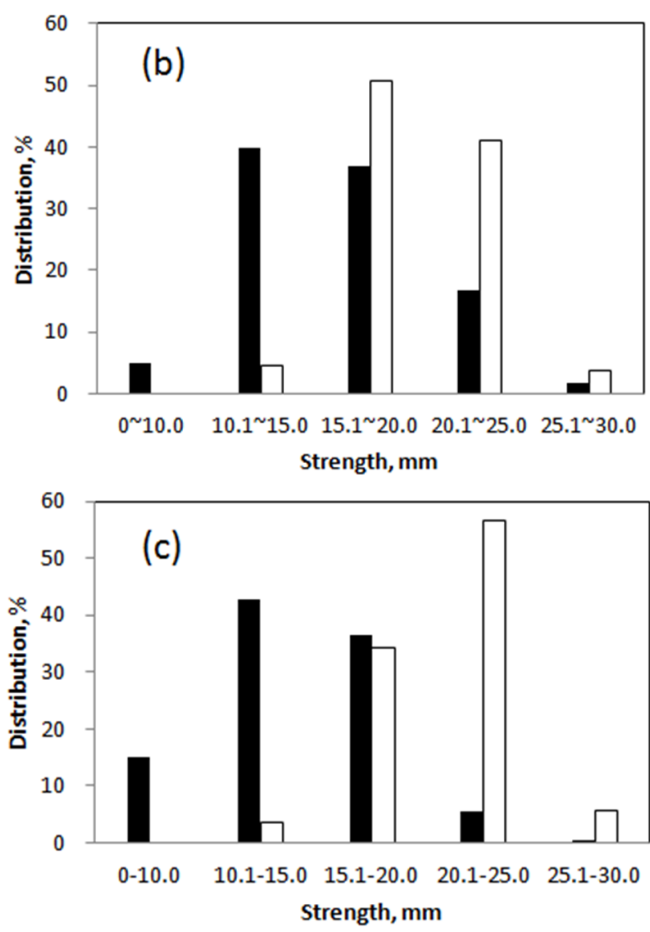

Fig. 2. Distribution of the strength with land use types. (a) Upland, (b) Orchard, (c) Paddy.

표토 $62.9 \%$, 심토 $81.9 \%$ 가 개량대상으로 논토양의 다짐상 태가 상당하며, 최대로 분포하는 범위는 표토 $1.21-1.40 \mathrm{Mg}$ $\mathrm{m}^{-3}$, 심토 $1.41-1.60 \mathrm{Mg} \mathrm{m}^{-3}$ 로 개량기준 경계에서 가장 많 은 분포를 보임을 알 수 있었다. 따라서 경계선 범위에 있는 농경지를 집중적으로 관리하는 것이 비옥도를 높이는데 관 건이 된다고 할 수 있겠다. 용적밀도와 경도는 논토양과 과 수원 토양에 비하여 밭토양이 대체로 높은 값의 분포가 많 았으며, 단 표토 경도는 논토양과 과수원 토양에 비하여 밭 토양에서 낮은 값에서 높은 분포를 보였다. 토양의 다짐상 태를 측정하는 지표로 사용되는 (Panayiotopoulos et al., 1994) 용적밀도와 경도는 두 값이 일관된 경향을 보였고, 밭 토양 표토는 잦은 경운작업으로 낮은 값을 보였다. 밭토양 이 논토양이나 과수원토양에 비해 용적밀도, 경도가 큰 것 은 유기물 함량이 낮고 수분함량이 적은 것에서 그 이유가 있는 것으로 판단된다. 유기물 함량이 가장 많은 범위를 보 인 과수원 토양과 논토양은 표토가 $20.1 \sim 30.0 \mathrm{~mm}$ (각각
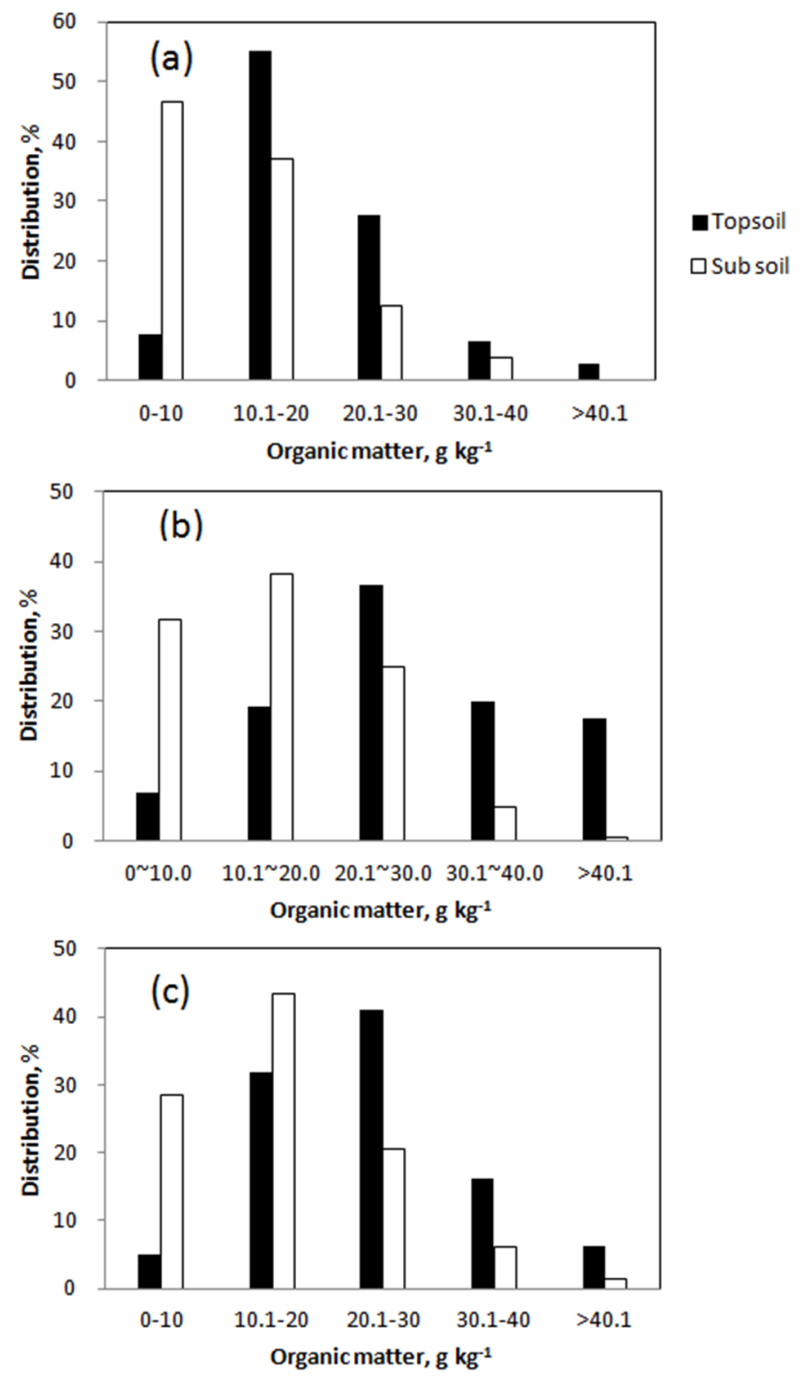

Fig. 3. Distribution of the organic matter with land use types. (a) Upland, (b) Orchard, (c) Paddy.

$37 \%, 41 \%$ ), 심토가 $10.1 \sim 20.0 \mathrm{~mm}$ (각각 $38 \%, 43 \%$ ), 밭토 양은 표토가 10.1 20.0 mm (55\%), 심토가 0 10 mm (47\%) 로 밭토양의 유기물 함량이 낮은 값에서의 분포가 높 았다. 유기물 함량은 토양에 투입되는 절대량과 투입된 후 토양 내 유기물 분해속도, 토양 중 유기물 보유능력에 따라 결정되며, 이 때 유기물 분해속도는 지온과 토양수분에 의 해 따라 달라진다 (Smith et al., 2005; Sleutel et al., 2007). 과수원은 가축분 퇴비의 투입이 많기 때문에 높은 유기물 수준을 유지하게 되며, 논은 담수상태를 유지하기 때문에 토양 내 유기물의 분해속도를 늦추고 따라서 유기물 이 높게 유지되는 조건을 갖고 있다. 한편 밭토양은 대개 경 사지에 위치하며 연중 초생피복 상태의 과수원 비해 상대적 으로 나대지 상태이기 때문에 토양침식에 대해 취약하여 토 양유실과 함께 유기물의 유실이 많다. 이상의 환경적, 농경 적, 입지적 특성을 생각할 때 밭토양의 유기물 함량이 낮은 결과를 예상할 수 있으며, 따라서 밭을 관리하는데 있어 이 점을 참고해야 한다. 
토양물리성 요인 간 상관분석 밭토양 표토에서는 용 적밀도와 기상률 $(\mathrm{R}=-0.75, \mathrm{p}\langle 0.001)$, 중량수분함량 $(\mathrm{R}=-0.34$, $\mathrm{p}<0.01)$, 유기물 함량 $(\mathrm{R}=-0.22, \mathrm{p}<0.05)$ 과는 음의 상관관 계, 경도 $(\mathrm{R}=0.48, \mathrm{p}\langle 0.001)$ 와는 양의 상관관계를 보였으 며, 경도와 기상률 $(\mathrm{R}=-0.34, \mathrm{p}<0.01)$, 모래함량 $(\mathrm{R}=-0.30$, $\mathrm{p}\langle 0.05)$ 과는 음의 상관관계를, 미사함량 $(\mathrm{R}=0.22, \mathrm{p}\langle 0.05)$, 점토함량 $(\mathrm{R}=0.37, \mathrm{p}\langle 0.01)$ 과는 양의 상관관계를 보였다. 심토에서는 이외에 용적밀도와 모래함량 간에 음의 상관관 계 $(\mathrm{R}=-0.38, \mathrm{p}\langle 0.001)$ 를 보였다.

과수원 토양 표토에서는 용적밀도와 기상률 $(\mathrm{R}=-0.58$, $\mathrm{p}\langle 0.001)$, 중량수분함량 $(\mathrm{R}=-0.58, \mathrm{p}\langle 0.001)$, 유기물 함량 $(\mathrm{R}=-0.58, \mathrm{p}\langle 0.001)$ 과는 음의 상관관계, 경도 $(\mathrm{R}=0.61$, $\mathrm{p}\langle 0.001)$ 와는 양의 상관관계를 보였으며, 경도와 기상률 $(\mathrm{R}=-0.3, \mathrm{p}<0.001)$, 모래함량 $(\mathrm{R}=-0.26, \mathrm{p}<0.001)$, 중량수 분함량 $(\mathrm{R}=-0.42, \mathrm{p}<0.001)$, 유기물 함량 $(\mathrm{R}=-0.38, \mathrm{p}<0.001)$ 과는 음의 상관관계를, 미사함량 $(\mathrm{R}=0.25, \mathrm{p}<0.001)$, 점토 함량 $(\mathrm{R}=0.14, \mathrm{p}\langle 0.05)$ 과는 양의 상관관계를 보였다. 심토 에서는 경도와 유기물 간의 상관관계가 유의하지 않았다.

논토양 표토에서는 용적밀도와 기상률 $(\mathrm{R}=-0.28, \mathrm{p}\langle 0.001)$, 중량수분함량 $(\mathrm{R}=-0.66, \mathrm{p}\langle 0.001)$, 유기물 함량 $(\mathrm{R}=-0.35$, $\mathrm{p}<0.001)$, 점토함량 $(\mathrm{R}=-0.33, \mathrm{p}<0.001)$ 과는 음의 상관관 계, 모래함량 $(\mathrm{R}=0.24, \mathrm{p}\langle 0.001)$, 경도 $(\mathrm{R}=0.25, \mathrm{p}\langle 0.001)$ 와는 양의 상관관계를 보였으며, 경도와 중량수분함량 $(\mathrm{R}=$ $-0.47, \mathrm{p}\langle 0.001)$, 유기물 함량 $(\mathrm{R}=-0.15, \mathrm{p}<0.05)$ 과는 음의 상관관계를, 기상률 $(\mathrm{R}=0.27, \mathrm{p}<0.001)$ 과는 양의 상관관계 를 보였다. 심토에서는 경도와 기상률 $(\mathrm{R}=-0.18, \mathrm{p}\langle 0.01)$, 중량수분함량 $(\mathrm{R}=-0.19, \mathrm{p}\langle 0.01)$ 과는 음의 상관관계, 미사 함량 $(\mathrm{R}=0.20, \mathrm{p}<0.001)$ 과는 양의 상관관계를 보였다.

용적밀도와 기상률, 중량수분함량, 유기물 함량 간에 음 의 상관관계, 경도와는 양의 상관관계가 공통적으로 나타났 다. 밭토양에서는 용적밀도와 기상률 간의 상관계수 (표토, -0.75 ; 심토, -0.62$)$ 는 비교적 높았으며, 과수원 토양에서 는 표토는 용적밀도와 경도 간의 상관계수가 -0.61 , 심토는 기상률 간의 상관계수가 -0.62 였으며, 논토양에서는 중량 수분함량 간의 상관계수(표토, -0.66 ; 심토, -0.64 )가 높은 것으로 나타났다. 용적밀도는 일정부피에 고상입자가 차지 하는 비율로 공극률과 반대개념이며 공극률은 토양 내 공기 와 수분으로 구성되기 때문에, 수분이 높은 토양은 용적밀 도와 토양수분함량 간에 관계가 있으며, 토양 내 기상률의 비율이 높은 토양은 용적밀도와 기상률 간에 관계가 있다. 즉 건조한 상태가 자주 나타나는 밭토양에서는 기상률 간의 상관계수가 가장 높았고, 밭토양에 비해 습한 상태로 유지 되며 유기물 함량이 높은 과수원 토양에서는 기상률, 중량 수분함량, 유기물 함량 모두 상관계수가 높게 나타났으며, 담수상태를 유지하는 논토양에서는 표토, 심토 모두 중량수 분함량 간의 상관계수가 가장 높은 것으로 나타났다.
경도는 밭토양에서는 기상률, 모래함량과는 음의 상관관 계, 미사, 점토함량과는 양의 상관관계를 보였으며, 과수원 토양에서는 기상률, 모래함량 외에 중량수분함량 및 유기물 함량과 음의 상관관계를 미사, 점토함량과는 양의 상관관계 를 보였다. 논토양은 표토에서는 중량수분함량, 유기물 함 량과는 음의 상관관계를, 기상률과는 양의 상관관계를 보였 으며, 심토에서는 중량수분함량, 기상률, 모래함량과는 음 의 상관관계, 미사함량과는 양의 상관관계를 보였다. 공통 적으로 경도는 입자크기에 따라 모래함량과는 음의 상관관 계를, 미사함량 및 점토함량과는 양의 상관관계를 보였는 데, 이는 미사와 점토에 의해 형성되는 공극의 치밀성과 입 자의 점착성 이 경도에 영향을 미치는 것으로 생각된다. 이 상의 결과는 유기물이 토양구조를 안정화시키고 물리적 퇴 화에 대한 저항성을 높이며 (Cochrane and Aylmore, 1994), 용적밀도와 토양 경도를 감소시킨다 (Carter, 2002) 는 보 고와 일치하였다. 따라서 유기물 함량이 높은 분포를 보인 과수원 토양과 논토양이 용적밀도 값이 낮은 분포를 보인 것과 연결하여 생각할 수 있다.

토지이용별 토양물리성 모델 예측 토양다짐에 영향 을 끼치는 다양한 요인들에 대한 평가의 용이성을 위해 다 짐상태의 측정지표로 사용되는 용적밀도에 대해 다중 선형 회귀분석을 실시하였다.

밭토양 표토의 용적밀도는 경도 $\left(\mathrm{R}^{2}=0.23, \mathrm{p}<0.001\right)$, 중 량수분함량 $\left(\mathrm{R}^{2}=0.08, \mathrm{p}\langle 0.01)\right.$, 유기물 함량 $\left(\mathrm{R}^{2}=0.05\right.$, $\mathrm{p}<0.01)$ 을 변수로 하며 회귀식은 $36 \%$ 의 설명력을 갖았으며 ( $\mathrm{p}<0.001)$, 심토의 용적밀도는 경도 $\left(\mathrm{R}^{2}=0.26, \mathrm{p}\langle 0.001)\right.$, 유 기물 함량 $\left(\mathrm{R}^{2}=0.08, \mathrm{p}\langle 0.01)\right.$, 점토함량 $\left(\mathrm{R}^{2}=0.05, \mathrm{P}<0.01\right)$ 을 변수로 하며 회귀식은 $40 \%$ 의 설명력을 갖었다 $(\mathrm{p}<0.001)$.

과수원 토양 표토의 용적밀도는 경도 $\left(\mathrm{R}^{2}=0.38, \mathrm{p}\langle 0.001)\right.$, 중량수분함량 $\left(\mathrm{R}^{2}=0.07, \mathrm{p}<0.001\right)$, 유기물 함량 $\left(\mathrm{R}^{2}=0.14\right.$, $\mathrm{p}<0.001)$ 에 대한 선형 회귀식으로 설명력은 $59 \%$ ( $\mathrm{p}<0.001$ ), 심토의 용적밀도는 경도 $\left(\mathrm{R}^{2}=0.09, \mathrm{p}<0.001\right)$, 중량수분함량 $\left(\mathrm{R}^{2}=0.06, \mathrm{p}\langle 0.001)\right.$, 유기물 함량 $\left(\mathrm{R}^{2}=0.022, \mathrm{p}<0.001\right)$ 에 대 한 선형 회귀식으로 $38 \%$ 로 설명되었다 ( $\mathrm{p}\langle 0.001)$.

논토양 표토의 용적밀도는 경도 $\left(\mathrm{R}^{2}=0.01, \mathrm{p}\langle 0.05)\right.$, 중량 수분함량 $\left(\mathrm{R}^{2}=0.44, \mathrm{p}\langle 0.001)\right.$, 유기물함량 $\left(\mathrm{R}^{2}=0.01, \mathrm{p}\langle 0.05)\right.$, 점토함량 $\left(\mathrm{R}^{2}=0.05, \mathrm{p}\langle 0.001)\right.$, 모래함량 $\left(\mathrm{R}^{2}=0.01, \mathrm{p}\langle 0.01)\right.$ 등 5 요소의 모델로 예측되었으며 ( $\mathrm{p}<0.001)$, 심토의 용적밀 도는 경도 $\left(\mathrm{R}^{2}=0.04, \mathrm{p}\langle 0.001)\right.$, 중량수분함량 $\left(\mathrm{R}^{2}=0.41, \mathrm{p}<\right.$ $0.001)$, 유기물함량 $\left(\mathrm{R}^{2}=0.01, \mathrm{p}\langle 0.05)\right.$, 점토함량 $\left(\mathrm{R}^{2}=0.01\right.$, $\mathrm{p}\langle 0.05)$, 모래함량 $\left(\mathrm{R}^{2}=0.01, \mathrm{p}\langle 0.01)\right.$ 등 5요소의 모델이며 ( $\mathrm{p}\langle 0.001)$, 표토, 심토 각각 $52 \%, 47 \%$ 를 설명할 수 있다.

대체로 용적밀도에 영향을 끼치는 인자는 경도, 중량수 분함량, 토양입자, 유기물 함량인 것으로 나타났으며, 토지 이용별로 이들 인자들의 영향은 각기 다르게 나타났다. 
Table 1. Correlation of physical properties for upland topsoil.

\begin{tabular}{|c|c|c|c|c|c|c|c|c|c|}
\hline & $\mathrm{BD}^{\dagger}$ & $\overline{\mathrm{LP}^{\ddagger}}$ & $\mathrm{GP}^{\S}$ & sand & silt & clay & Strength & GWC $^{\pi}$ & $\overline{\mathrm{OM}^{\phi}}$ \\
\hline $\mathrm{BD}^{\dagger}$ & 1.00 & & & & & & & & \\
\hline $\mathrm{LP}^{\ddagger}$ & 0.04 & 1.00 & & & & & & & \\
\hline $\mathrm{GP}^{\S}$ & $-0.75^{* * * *}$ & $-0.69^{* * *}$ & 1.00 & & & & & & \\
\hline sand & -0.07 & $-0.27^{*}$ & 0.23 & 1.00 & & & & & \\
\hline silt & $>-0.01$ & $0.29^{*}$ & -0.19 & $-0.95^{* * *}$ & 1.00 & & & & \\
\hline clay & 0.17 & 0.18 & $-0.24^{*}$ & $-0.87^{* * *}$ & $0.68^{* * *}$ & 1.00 & & & \\
\hline Strength & $0.48^{* * *}$ & -0.04 & $-0.34^{* *}$ & $-0.30^{*}$ & $0.22^{*}$ & $0.37^{* *}$ & 1.00 & & \\
\hline GWC $^{\mathbb{I}}$ & $-0.34^{* *}$ & 0.18 & 0.12 & -0.03 & 0.03 & $<0.01$ & -0.13 & 1.00 & \\
\hline $\mathrm{OM}^{\phi}$ & $-0.22^{*}$ & 0.10 & 0.08 & -0.11 & 0.11 & 0.08 & 0.06 & 0.10 & 1.00 \\
\hline
\end{tabular}

${ }^{*}, \mathrm{p}<0.05 ;^{* *}, \mathrm{p}<0.01 ;{ }^{* * *}, \mathrm{p}<0.001$.

${ }^{\dagger} \mathrm{BD}$, Bulk Density; ${ }^{\ddagger} \mathrm{LP}$, Liquid phase ratio; ${ }^{\S} \mathrm{GP}$, Gas phase ratio; ${ }^{\natural} \mathrm{GWC}$, Gravitational Water Content; ${ }^{\oint}$ OM, Organic Matter.

Table 2. Correlation of physical properties for upland subsoil.

\begin{tabular}{|c|c|c|c|c|c|c|c|c|c|}
\hline & $\mathrm{BD}^{\dagger}$ & $\mathrm{LP}^{\ddagger}$ & $\mathrm{GP}^{\S}$ & sand & silt & clay & Strength & GWC $^{\mathbb{f}}$ & $\mathrm{OM}^{\phi}$ \\
\hline $\mathrm{BD}^{\dagger}$ & 1.00 & & & & & & & & \\
\hline $\mathrm{LP}^{\ddagger}$ & -0.01 & 1.00 & & & & & & & \\
\hline $\mathrm{GP}^{\S}$ & $-0.62^{* * * *}$ & $-0.78^{* * * *}$ & 1.00 & & & & & & \\
\hline sand & $-0.38^{* * *}$ & $-0.39^{* * *}$ & $0.55^{* * *}$ & 1.00 & & & & & \\
\hline silt & $0.24^{*}$ & $0.45^{* * *}$ & $-0.51^{* * *}$ & $-0.92^{* * *}$ & 1.00 & & & & \\
\hline clay & $0.49^{* * *}$ & $0.21^{*}$ & $-0.47^{* * *}$ & $-0.85^{* * *}$ & $0.59^{* * *}$ & 1.00 & & & \\
\hline Strength & $0.51^{* * *}$ & 0.13 & $-0.43^{* * *}$ & $-0.42^{* * *}$ & $0.30^{*}$ & $0.48^{* * *}$ & 1.00 & & \\
\hline GWC" & $-0.03^{* *}$ & 0.28 & -0.21 & -0.18 & 0.15 & 0.16 & 0.03 & 1.00 & \\
\hline $\mathrm{OM}^{\oint}$ & $-0.22^{*}$ & 0.10 & $0.08^{*}$ & -0.11 & 0.11 & 0.08 & 0.06 & 0.10 & 1.00 \\
\hline
\end{tabular}

, $\mathrm{p}<0.05 ;{ }^{* *}, \mathrm{p}<0.01 ;{ }^{* * *}, \mathrm{p}<0.001$.

${ }^{\dagger} \mathrm{BD}$, Bulk Density; ${ }^{\ddagger} \mathrm{LP}$, Liquid phase ratio; ${ }^{\S} \mathrm{GP}$, Gas phase ratio; ${ }^{\natural} \mathrm{GWC}$, Gravitational Water Content; ${ }^{\S}$ OM, Organic Matter.

Table 3. Correlation of physical properties for orchard topsoil.

\begin{tabular}{|c|c|c|c|c|c|c|c|c|c|}
\hline & $\mathrm{BD}^{\dagger}$ & $\mathrm{LP}^{\ddagger}$ & $\mathrm{GP}^{\S}$ & sand & silt & clay & Strength & GWC" $^{\pi}$ & $\overline{\mathrm{OM}}^{9}$ \\
\hline $\mathrm{BD}^{\dagger}$ & 1.00 & & & & & & & & \\
\hline $\mathrm{LP}^{\ddagger}$ & $-0.15^{*}$ & 1.00 & & & & & & & \\
\hline $\mathrm{GP}^{\S}$ & $-0.58^{* * *}$ & $-0.72^{* * *}$ & 1.00 & & & & & & \\
\hline sand & 0.02 & $-0.16^{*}$ & 0.12 & 1.00 & & & & & \\
\hline silt & $>-0.01$ & $0.14^{*}$ & -0.11 & $-0.86^{* * *}$ & 1.00 & & & & \\
\hline clay & -0.03 & 0.10 & -0.06 & $-0.64^{* * *}$ & $0.16^{*}$ & 1.00 & & & \\
\hline Strength & $0.61^{* * *}$ & $-0.16^{*}$ & $-0.30^{* * *}$ & $-0.26^{* * *}$ & $0.25^{* * *}$ & $0.14^{*}$ & 1.00 & & \\
\hline GWC" & $-0.58^{* * *}$ & $0.87^{* * *}$ & $-0.31^{* * *}$ & -0.10 & 0.09 & 0.06 & $-0.42^{* * *}$ & 1.00 & \\
\hline $\mathrm{OM}^{\phi}$ & $-0.58^{* * *}$ & $0.17^{*}$ & $0.27^{* * *}$ & -0.08 & 0.05 & 0.08 & $-0.38^{* * *}$ & $0.36^{* * *}$ & 1.00 \\
\hline
\end{tabular}

${ }^{*}, \mathrm{p}<0.05 ;{ }^{* *}, \mathrm{p}<0.01 ;{ }^{* * *}, \mathrm{p}<0.001$.

${ }^{\dagger} \mathrm{BD}$, Bulk Density; ${ }^{\ddagger} \mathrm{LP}$, Liquid phase ratio; ${ }^{\S} \mathrm{GP}$, Gas phase ratio; ${ }^{\natural} \mathrm{GWC}$, Gravitational Water Content; ${ }^{\oint}$ OM, Organic Matter.

앞의 상관분석에서 용적밀도와 기상률의 상관관계가 유 의하게 나왔지만 (Table 1-6), 회귀분석에서는 기상률에 대 해 유의성이 인정되지 않았다. 이는 경도와 기상률이 유의 한 상관관계를 가지며 (Table 1-6) 용적밀도에 미치는 영향 이 기상률보다 경도가 상대적으로 크기 때문에 회귀식에서
경도가 기상률 인자의 영향을 포함하여 나타내고 기상률은 유의하지 않은 것으로 판단된다. 밭토양과 과수원 토양은 경도의 결정계수가 다른 인자들에 비하여 높은 한편, 논토 양은 중량수분함량에서 높게 나타나 밭토양과 과수원 토양 에서는 경도 측정으로 용적밀도의 정도를 예상할 수 있으 
Table 4. Correlation of physical properties for orchard subsoil.

\begin{tabular}{|c|c|c|c|c|c|c|c|c|c|}
\hline & $\mathrm{BD}^{\dagger}$ & $\overline{L \mathrm{LP}^{\ddagger}}$ & $\overline{G^{\prime} P^{\S}}$ & sand & silt & clay & Strength & GWC" $^{\text {G }}$ & $\mathrm{OM}^{\phi}$ \\
\hline$\overline{\mathrm{BD}^{\dagger}}$ & 1.00 & & & & & & & & \\
\hline $\mathrm{LP}^{\ddagger}$ & -0.01 & 1.00 & & & & & & & \\
\hline $\mathrm{GP}^{\S}$ & $-0.62^{* * *}$ & $-0.78^{* * *}$ & 1.00 & & & & & & \\
\hline sand & 0.09 & $-0.34^{* * *}$ & $0.21^{* *}$ & 1.00 & & & & & \\
\hline silt & -0.08 & $0.29^{* * *}$ & $-0.18^{*}$ & $-0.90^{* * *}$ & 1.00 & & & & \\
\hline clay & -0.06 & $0.29^{* * *}$ & $-0.18^{*}$ & $-0.75^{* * *}$ & $0.40^{* * *}$ & 1.00 & & & \\
\hline Strength & $0.36^{* * *}$ & -0.06 & $-0.17^{*}$ & $-0.29^{* * *}$ & $0.24^{* *}$ & $0.26^{* * *}$ & 1.00 & & \\
\hline GWC" & $-0.39^{* * *}$ & $0.92^{* * *}$ & $-0.47^{* * *}$ & $-0.35^{* * *}$ & $0.30^{* * *}$ & $0.28^{* * *}$ & $-0.21^{* *}$ & 1.00 & \\
\hline $\mathrm{OM}^{\oint}$ & $-0.47^{* * *}$ & 0.02 & $0.28^{* * *}$ & $-0.25^{* * *}$ & $0.19^{*}$ & $0.25^{* * *}$ & -0.12 & $0.21^{* *}$ & 1.00 \\
\hline
\end{tabular}

* $\mathrm{p}<0.05 ;{ }^{* *}, \mathrm{p}<0.01 ;{ }^{* * *}, \mathrm{p}<0.001$.

${ }^{\dagger} \mathrm{BD}$, Bulk Density; ${ }^{\ddagger} \mathrm{LP}$, Liquid phase ratio; ${ }^{\S} \mathrm{GP}$, Gas phase ratio; ${ }^{\natural} \mathrm{GWC}$, Gravitational Water Content; ${ }^{\S}$ OM, Organic Matter.

Table 5. Comelation of physical properties for paddy topsoil.

\begin{tabular}{|c|c|c|c|c|c|c|c|c|c|}
\hline & $\mathrm{BD}^{\dagger}$ & $\overline{\mathrm{LP}^{\ddagger}}$ & $\mathrm{GP}^{\S}$ & sand & silt & clay & Strength & GWC" & $\mathrm{OM}^{9}$ \\
\hline $\mathrm{BD}^{\dagger}$ & 1.00 & & & & & & & & \\
\hline $\mathrm{LP}^{\ddagger}$ & $-0.13^{*}$ & 1.00 & & & & & & & \\
\hline $\mathrm{GP}^{\S}$ & $-0.28^{* * *}$ & $-0.38^{* * *}$ & 1.00 & & & & & & \\
\hline sand & $0.24^{* * *}$ & $-0.28^{* * *}$ & -0.07 & 1.00 & & & & & \\
\hline silt & -0.09 & $0.34^{* * *}$ & 0.04 & $-0.88^{* * *}$ & 1.00 & & & & \\
\hline clay & $-0.33^{* * *}$ & -0.02 & 0.07 & $-0.55^{* * *}$ & 0.07 & 1.00 & & & \\
\hline Strength & $0.25^{* * *}$ & $-0.43^{* * *}$ & $0.27^{* * *}$ & -0.04 & 0.06 & -0.03 & 1.00 & & \\
\hline GWC" & $-0.66^{* * *}$ & $0.81^{* * *}$ & $-0.14^{*}$ & $-0.32^{* * *}$ & $0.30^{* * * *}$ & $0.15^{*}$ & $-0.47^{* * *}$ & 1.00 & \\
\hline $\mathrm{OM}^{\phi}$ & $-0.35^{* * *}$ & $0.26^{* * *}$ & 0.04 & $-0.13^{*}$ & $0.10^{*}$ & 0.09 & $-0.15^{*}$ & $0.39^{* * *}$ & 1.00 \\
\hline
\end{tabular}

, $\mathrm{p}<0.05 ;^{* *}, \mathrm{p}<0.01 ;{ }^{* * *}, \mathrm{p}<0.001$.

${ }^{\dagger} \mathrm{BD}$, Bulk Density; ${ }^{\ddagger} \mathrm{LP}$, Liquid phase ratio; ${ }^{\S} \mathrm{GP}$, Gas phase ratio; ${ }^{\ddagger} \mathrm{GWC}$, Gravitational Water Content; ${ }^{\oint}$ OM, Organic Matter.

Table 6. Comelation of physical properties for paddy subsoil.

\begin{tabular}{|c|c|c|c|c|c|c|c|c|c|}
\hline & $\mathrm{BD}^{\dagger}$ & 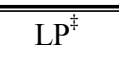 & $\mathrm{GP}^{\S}$ & sand & silt & clay & Strength & GWC $^{\pi}$ & $\mathrm{OM}^{9}$ \\
\hline $\mathrm{BD}^{\dagger}$ & 1.00 & & & & & & & & \\
\hline $\mathrm{LP}^{\ddagger}$ & $-0.25^{* * *}$ & 1.00 & & & & & & & \\
\hline $\mathrm{GP}^{\S}$ & $-0.54^{* * *}$ & $-0.68^{* * * *}$ & 1.00 & & & & & & \\
\hline sand & $0.12^{*}$ & $-0.43^{* * *}$ & $0.28^{*}$ & 1.00 & & & & & \\
\hline silt & -0.07 & $0.45^{* * *}$ & $-0.33^{* * *}$ & $-0.90^{* * *}$ & 1.00 & & & & \\
\hline clay & $-0.13^{*}$ & $0.15^{*}$ & -0.03 & $-0.63^{* * *}$ & $0.22^{* * *}$ & 1.00 & & & \\
\hline Strength & $0.32^{* * *}$ & -0.07 & $-0.18^{* *}$ & -0.13 & $0.20^{* * *}$ & -0.06 & 1.00 & & \\
\hline GWC" & $-0.64^{* * *}$ & $0.89^{* * *}$ & $-0.29^{* * *}$ & $-0.39^{* * *}$ & $0.39^{* * *}$ & $0.17^{* *}$ & $-0.19^{* *}$ & 1.00 & \\
\hline $\mathrm{OM}^{\phi}$ & $-0.29^{* * *}$ & $0.28^{* * *}$ & -0.02 & -0.01 & 0.06 & -0.09 & -0.03 & $0.35^{* * *}$ & 1.00 \\
\hline
\end{tabular}

${ }^{*}, \mathrm{p}<0.05 ;{ }^{* *}, \mathrm{p}<0.01 ;{ }^{* * *}, \mathrm{p}<0.001$.

${ }^{\dagger} \mathrm{BD}$, Bulk Density; ${ }^{\ddagger} \mathrm{LP}$, Liquid phase ratio; ${ }^{\S} \mathrm{GP}$, Gas phase ratio; ${ }^{\ddagger} \mathrm{GWC}$, Gravitational Water Content; ${ }^{\oint}$ OM, Organic Matter.

나, 논토양에서는 수분상태의 영향을 많이 받기 때문에 경 도 측정으로 용적밀도를 예측하기에 무리가 있을 것으로 판 단된다 (Table 7).

밭토양 심토와 논토양의 용적밀도는 이외에 토양입자에 대해서 유의성이 있는 것으로 나타났는데, 밭토양 심토는
점토함량이 증가함에 따라 용적밀도가 증가하는 한편, 논토 양은 점토함량과 모래함량이 증가함에 따라 용적밀도가 감 소하는 것으로 나타나 논과 밭이 점토함량에 대해 토양다짐 의 반응이 다름을 볼 수 있다. 일반적으로 입자가 작은 토양 이 입자가 큰 토양보다 다짐이 잘 일어나는 것으로 알려져 
Table 7. Analysis of regression with land use types.

\begin{tabular}{|c|c|c|c|c|c|c|c|c|c|}
\hline \multirow{2}{*}{ Land use type } & \multirow{2}{*}{$\mathrm{n}$} & \multirow{2}{*}{ Depth } & \multirow{2}{*}{$\mathrm{R}^{2}$} & \multirow{2}{*}{ Intercept } & \multicolumn{5}{|c|}{ Parameter Estimate (Partial R-square) } \\
\hline & & & & & Strength & $\mathrm{GWC}^{\dagger}$ & $\mathrm{OM}^{\ddagger}$ & Clay & Sand \\
\hline \multirow{2}{*}{ Upland } & \multirow{2}{*}{105} & Topsoil & 0.36 & $1.414^{* * *}$ & $\begin{array}{c}0.017^{* * *} \\
(0.23)\end{array}$ & $\begin{array}{c}-0.009^{* *} \\
(0.08)\end{array}$ & $\begin{array}{c}-0.004^{* *} \\
(0.05)\end{array}$ & - & - \\
\hline & & Subsoil & 0.40 & $1.380^{* * *}$ & $\begin{array}{c}0.011^{* * *} \\
(0.26)\end{array}$ & - & $\begin{array}{c}-0.004^{* *} \\
(0.08)\end{array}$ & $\begin{array}{l}0.004^{* *} \\
(0.05)\end{array}$ & - \\
\hline \multirow{2}{*}{ Orchard } & \multirow{2}{*}{246} & Topsoil & 0.59 & $1.288^{* * *}$ & $\begin{array}{c}0.015^{* * *} \\
(0.38)\end{array}$ & $\begin{array}{c}-0.006^{* * *} \\
(0.07)\end{array}$ & $\begin{array}{c}-0.004^{* * *} \\
(0.14)\end{array}$ & - & - \\
\hline & & Subsoil & 0.38 & $1.425^{* * *}$ & $\begin{array}{c}0.011^{* * *} \\
(0.09)\end{array}$ & $\begin{array}{c}-0.007^{* * *} \\
(0.06)\end{array}$ & $\begin{array}{c}-0.006^{* * *} \\
(0.22)\end{array}$ & - & - \\
\hline \multirow{2}{*}{ Paddy } & \multirow{2}{*}{408} & Topsoil & 0.52 & $1.961^{* * *}$ & $\begin{array}{c}-0.004^{*} \\
(0.01)\end{array}$ & $\begin{array}{c}-0.014^{* * *} \\
(0.44)\end{array}$ & $\begin{array}{c}-0.002^{*} \\
(0.01)\end{array}$ & $\begin{array}{c}-0.005^{* * *} \\
(0.05)\end{array}$ & $\begin{array}{c}-0.001^{* *} \\
(0.01)\end{array}$ \\
\hline & & Subsoil & 0.47 & $1.864^{* * *}$ & $\begin{array}{c}0.008^{* * *} \\
(0.04)\end{array}$ & $\begin{array}{c}-0.017^{* * *} \\
(0.41)\end{array}$ & $\begin{array}{c}-0.001^{*} \\
(0.01)\end{array}$ & $\begin{array}{c}-0.002^{*} \\
(0.01)\end{array}$ & $\begin{array}{c}-0.001^{* *} \\
(0.01)\end{array}$ \\
\hline
\end{tabular}

${ }^{*}, \mathrm{p}<0.05 ;{ }^{* *}, \mathrm{p}<0.01 ;{ }^{* * *}, \mathrm{p}<0.001$.

${ }^{\dagger} \mathrm{GWC}$, Gravitational water content.

${ }^{\ddagger} \mathrm{OM}$, Organic matter.

있으며, 점토함량이 $30 \%$ 이하에서는 점토함량이 증가함에 따라 압축지수 (compression index) 가 증가하기 때문에 (Larson et al., 1980; Imhoff et al., 2004) 용적밀도도 증 가한다. 논토양에서 용적밀도에 대해 점토함량이 부의 관계 를 보인 것은 다짐이 일어나는 토양수분상태가 담수조건이 라는 것에서 그 이유를 찾을 수 있겠다. 토양다짐이 일어날 때 토양수분함량은 매우 중요한 조건으로(Van Ouwerkerk and Soane, 1994), 외부에서 힘을 가했을 때 적정수분범위 내에서 수분이 증가함에 따라 토양다짐은 증가하나, 그 이 상의 수분이 되면 다짐은 오히려 줄어든다 (Kondo and Dias Junior, 1999). Cho et al. (2012) 은 사양토와 미사질 식양토를 대상으로 토양수분함량을 달리한 토양다짐 실험 에서, 토양수분함량이 증가함에 따라 다짐이 증가하다가 수 분한계범위를 넘었을 때 다짐의 변화가 작아졌으며, 특히 미사질식양토에서 다짐의 변화가 거의 없었다고 발표하였 다. 이는 점토함량이 많은 토양이 적정범위 이상의 토양수 분조건에서 압력이 가해질 때 다짐에 대한 반응이 더 작음 을 의미한다. 이상의 연구결과들을 종합해 볼 때 밭토양과 과수원토양은 적정수분범위 이내의 수분상태에서의 다짐의 양상, 즉 점토함량이 증가함에 따라 용적밀도가 증가하는 경향을 보이고, 논토양은 적정수분범위 이상의 수분상태에 서의 다짐의 양상, 즉 점토가 많은 토양이 오히려 다짐이 잘 일어나지 않는 경향을 보인 것으로 해석할 수 있겠다. 토양 다짐은 수분함량에 따라 그 양상이 민감하기 때문에 수분함 량에 대한 토양다짐의 변화를 이해하고 적정 수준의 토양수 분함량을 알기 위해서는 좀더 넓은 수분범위에서의 추가실 험 필요할 것으로 생각된다. 또한 토양특성마다 수분함량의 변화에 따라 다짐의 양상이 달라지기 때문에는 농작업시 경
작지의 토양특성 특히 점토함량을 파악하고 이에 따라 농작 업 계획을 세우는 것이 다짐에 의한 토양퇴화를 예방하는 관리방안이 될 수 있겠다.

용적밀도는 유기물 함량이 증가함에 따라 감소하는데 (Soane, 1990; Dexter, 2004; Dexter et al., 2005), 이에 대 해 유기물이 압축에 대한 저항성을 증가시키며, 기계적 압 력에 대해 토양의 탄력을 높여준다는 견해와(Soane, 1990) 이런 효과가 없다고 주장(Imhoff et al., 2004; Keller and Arvidsson, 2007) 도 있다. 한편 유기물은 토양구조를 좋게 하며 수분 보유력을 높이는 기능 이외에 유기물 무게 자체 가 작기 때문에 용적밀도를 감소시키는데 부수적인 효과도 있다는 것을 고려해 볼 수 있겠다. 특히 과수원 토양에서 용 적밀도에 대한 유기물의 영향력이 컸는데, 이는 과수원 토 양의 유기물 함량이 높아 용적밀도와 밀접한 관련성을 갖는 것으로 해석할 수 있다. 상관분석에서는 용적밀도와 유기물 의 상관계수가 논토양에서 밭토양에서보다 높게 나왔으나 회귀분석에서는 밭토양에서 용적밀도 값에 유기물이 미치 는 영향이 큰 것으로 나타났다. 논토양에서는 수분함량의 기여도가 매우 높아 용적밀도에 영향을 주는 요인을 종합적 으로 고려할 때 유기물의 영향이 상대적으로 작아진 것으로 생각된다.

\section{Conclusions}

본 연구에서는 다중선형 회귀를 통해 다양한 물리성 인 자(경도, 중량수분함량, 유기물 함량, 점토함량, 모래함량) 로 용적밀도에 대해 40 50\% 정도를 설명할 수 있었다. 다 섯 가지 인자만으로 용적밀도를 예측한다는 것은 어렵지만, 
특정 인자에 대한 영향력을 파악하고 토양관리에 대한 물리 성 기준이 없는 현실에서 관리지침으로 참고하는데 이 모델 식의 의의가 있을 것이다. 이상의 결과로 미루어 볼 때, 농 경지의 토양물리성 관리 측면을 고려할 때 토양수분과 함께 유기물 관리에 유념해야 함을 알 수 있으며, 특히 밭토양의 경우, 유기물 축적이 어려운 조건을 고려하여 적정 수준을 유지하여 다짐을 예방하는 것이 중요하다고 판단된다. 현재 우리나라 논토양 관리기준은 표토, 심토 등 층위로만 구분 되어 있는데, 논토양의 용적밀도에 토양입자가 직접적인 영 향을 끼친다는 점을 생각할 때 정밀관리를 위해서는 토성별 로 물리성 기준을 마련하는 것이 필요할 것으로 생각된다. 토양관리측면에서 토양다짐은 토양수분조건에 따라 그 양 상이 다양하기 때문에 적정 토양수분 조건에서 농작업을 하 는 것이 다짐으로 인한 토양퇴화를 예방하는 방안이라고 할 수 있겠다.

\section{References}

Akker, J.J.H. and Canarache, A. 2001. Two European concerted actions on subsoil compaction. Landnutzung and Landentwicklung 42:15-22.

Boizard, H., Richard, G., Roger-Estrade, J., Durr, C. and Boiffin, J. 2001. Cumulative effect of cropping systems on the structure of the tilled layer in northern France. Soil \& tillage Res. 64:149-164.

Busscher, W.J.1990. Adjustment of flat-tipped penetrometer resistance data to a common water content. ASAE. 33(2):519-524.

Carter, M.R. 2002. Soil quality for sustainable land management : organic matter and aggregation interactions that maintain soil functions. Agronomy J. 94:38-47.

Cassio, A.T., A.P. da Silva and P.L. Libardi. 1999. Soil physical quality of a Brazilian oxisol under two tillage systems using the least limiting water range approach. Soil \& Tillage Res. 52:223-232.

Cho H.R, Y.S. Zhang, K.H. Han, S.W. Yoon, S.H. Hyun. 2012. A study on the soil bulk density as affected by compression in column test. 2012 Conference on Soil Science Society America.

Cochrane, H.R. and Aylmore, L.A.G. 1994. The effects of plant roots on soil structure. In: Proceedings of 3rd Triennial Conference "Soils 94". 207-212.

Dexter, A.R. 2004. Soil physical quality. Part I. Theory, effects of soil texture, density, and organic matter, and effects on root growth. Geoderma 120:201-214.

Dexter, A.R., E.A. Czyz, M. Birkás, E. Diaz-Pereira, E. Dumitru, R. Enache, H. Fleige, R. Horn, K. Rajkaj, D. De La Rosa and C. Simota. 2005. SIDASS project, Part 3. The optimum and the range of water content for tillage further developments. Soil \& Tillage Res. 82, 29-37.
European Soil Framework Directive. 2006. Proposal for a directive of the European parliament and of the council establishing a framework for the protection of soil and amending directive 2004/35/EC, p30.

Flowers, M. and R. Lal. 1998. Axle load and tillage effect on soil physical properties and soybean grain yield on a mollic ochraqualf in northwest Ohio. Soil \& Tillage Res. 48:21-35.

German soil protection law. 1998. Gesetz zum Schutz des Bodens vom 17.03.1998. BGBI.I, p502.

Guerif, J. 1994. Effects of compaction on soil strength parameters. In:Soane, B.D., van Ouwerkerk, C. (Eds.), Soil compaction in crop production. Elsevier, Amsterdam, Netherlands. 191-214.

Lipiec, J., Ferrero, A., Giovanetti, V., Nosalewicz, A. and Turski, M. 2002. Response of structure to simulated trampling of woodland soil. Adv. Geoecol. 35:133-140.

Lipiec, J. and Hatano, R. 2003. Quantification of compaction effects on soil physical properties and crop growth. Geoderma. 116:107-136.

Hamza, M.A. and Anderson, W.K. 2003. Response of soil properties and grain yields to deep ripping and gypsum application in a compacted loamy sand soil contrasted with a sandy clay loam soil in Western Australia. Aust. J. Agric. Res. 54:273-282.

Han, K.H., H.J. Cho, S.K. Ha, H.R. Cho and S.H. Jeon. 2010. Soil physical properties of upland field as affected by different years with heavy agro-machine use. 2010 Conference of Korean soil \& fertilizer. 43(1):363-363.

Horn, R. and Rostek, J. 2000. Subsoil compaction processes-state of knowledge. In: Horn, R., van den Akker, J.J.H., and Arvidsson, J. (Eds.), Subsoil

compaction-distribution, processes and consequences. Adv. Geoecol. 32. Catena, Reiskirchen, Germany. 44-54.

Hur, B.K, S.K. Rim, Y.H. Kim and K.Y. Lee. 1997. Physico-chemical properties on the management groups of paddy soils in Korea. Korean J. Soil Sci. Fert. 30(1):62-66. Hur,B.K, Z.H.Kim, Y.S.Kim and Y.S.Park. 1993.

Relationship of soil particle size and organic matter content to the bulk density in paddy soil. Korean J. Soil Sci. Fert. 26(3):155-159.

Imhoff, S., A.P. da Silva and D. Fallow. 2004. Susceptibility to compaction, load support capacity and soil compressibility of Hapludox. Soil Sci. Soc. Am. J. 68:1724.

Imhoff, S., A.P. da Silva and D. Fallow. 2004. Susceptibility to compaction, load support capacity and soil compressibility of Hapludox. Soil Sci. Soc. Am. J. 68:17-24.

Jo, I.S., S.J. Cho and J.N. Im. 1977. A study on penetration of pea seedling taproots as influenced by strength of soil. Korean J. Soil Sci. Fert. 10(1):7-12. 
Jung, Y.S. and H.S. Lim. 1989. Influence of soil texture and bulk density on foot growth characteristics and nutrient influx rate of soybean plant. Korean J. Soil Sci. Fert. 22(3):221-227.

Keller, T. and J. Arvidsson. 2007. Compressive properties of some Swedish and Danish structured agricultural soils measured in uniaxial compression tests. Eur. J. Soil Sci. 58:1373-1381.

Kim, L.Y., H.J. Cho, S.D. Hong, and H.S. Lee. 2013. Amelioration guideline of soil physical properties in paddy rice fields based on soil survey of dominant soil series in Korea. J. Agr. Sci. Chungbuk Nat'l Univ. 29(2):49-54.

Kim, L.Y., H.J. Chol, S.O. Chung, W.Y. Park, and K.S. Lee. 2006. Determination of tillage depth based on physical properties of soil for rice production in Korea. Key engineer materials. 321-323:1229-1232.

Kondo, M.K. and Dias Junior and M.S. 1999. Soil compressibility of three latosols as a function of moisture and use. Revista Brasileira de Ciencia do Solo. 23:211-218.

Larson, W.E., S.C. Gupta and R.A. Useche. 1980. Compression of agricultural soils from eight soil orders. Soil Sci. Soc. Am. J. 44:450-457.

NIAST. 2000. Methods of soil and plant analysis. National Institute of Agricultural Science and Technology, RDA, NIAST. Suwon, Korea.

NIAST. 2010. Survey manual and analysis method for soil physical properties. National Institute of Agricultural Science and Technology, RDA, NIAST. Suwon, Korea.

NIAST. 2012. Monitoring Project on Agro-Environmental Quality. RDA, NIAST. Suwon, Korea.

Panayiotopoulos, K.P., C.P. Papadopoulou and A. Hathjioannidou. 1994. Compaction and penetration resistance of an Alfisol and Entisol and their influence on root growth of maize seedlings. Soil \& Tillage Res. 31:323-337.

Reynolds, W.D., B.T. Bowman, C.F. Drury, C.S. Tan and X. Lu. 2002. Indicators of good soil physical quality: density and storage parameters. Geoderma. 110:131-146.

Sleutel, S., S. De Neve and G. Hofman. 2007. Assessing causes of recent organic carbon losses from cropland soils by means of regional-scaled input balances for the case of Flanders (Belgium). Nutr. Cycl. Agroecosyst. 78:265-278 Smith, J., P. Smith, M. Wattenbach, S. Zaehle, R. Hiederer, R.J.A. Jones, L. Montanarella, M.D.A. Rounsevell, I. Reginster and F. Ewert. 2005. Projected changes in mineral soil carbon of European croplands and grasslands, 19902080. Global Change Biol. 11:2141-2152.

Soane, B.D. 1990. The role of organic matter in soil compactibility: A review of some practical aspects. Soil \& Tillage Res. 16:179-201.

Soane, B.D. and C. Van Ouwerkerk. 1995. Implications of soil compaction in crop production for the quality of the environment. Soil \& Tillage Res. 35:5-22.

Spoor, G. and Godwin, R.J. 1978. An experimental investigation into the deep loosening of soil by rigid tine. J. Agric. Eng. Res. 23:243-258.

Taylor, H.M. 1971. Effect of soil strength on seedling emergence, root growth and crop yield. Compaction of agricultural soils, American Society of Agri. Eng. 292-305. Van Ouwerkerk, C. and B.D. Soane. 1994. Conclusions and recommendations for further research on soil compaction in crop production. In: Soane, B.D., Van Ouwerkerk, C., (Eds.), Soil compaction in crop production. Dev. Agric. Eng. Elsevier, Amsterdam. 11:627-642. 